\title{
Períodos de Interferência das Plantas daninhas na Cultura do Algodão em Semeadura Adensada na Safrinha ${ }^{1}$
}

\author{
Periods of Weeds Interference in Cotton Yield in the Seeding Densified "Off Season" \\ RAIMONDI, M.A. ${ }^{2}$, OLIVEIRA JR., R.S. ${ }^{3}$, CONSTANTIN, J. ${ }^{3}$, FRANCHINI, L.H.M. ${ }^{3}$, BIFFE, D.F. ${ }^{3}$, \\ BLAINSKI, É. ${ }^{4}$ e RAIMONDI, R.T. ${ }^{3}$
}

\begin{abstract}
RESUMO - A semeadura adensada do algodoeiro na safrinha é uma estratégia adotada pelos cotonicultores para reduzir os custos de produção e aumentar a rentabilidade dessa atividade. O objetivo deste trabalho foi determinar os periodos de convivência e controle das plantas daninhas no algodoeiro em semeadura adensada na safrinha. O experimento foi conduzido na Fazenda Pouso Frio, em Chapadão do Sul-MS. A semeadura do cultivar BRS 293 ocorreu no dia 07/02/2010, adotando-se espaçamento de 0,45 m entre linhas e a densidade de 260 mil sementes por hectare. Os tratamentos constaram de dois grupos. No primeiro, a cultura foi mantida por períodos iniciais crescentes em convivência com plantas daninhas, após sua emergência, para determinação do PAI, e no segundo grupo, para determinação do PTPI, o algodoeiro permaneceu por períodos iniciais livre da matocompetição. Foram analisados períodos de $0,5,10,15,22,29,36,43,50,57,64,71$ e 165 dias após emergência (DAE) de convivência ou controle inicial das plantas daninhas. As plantas daninhas de maior importância relativa foram Bidens pilosa, Amaranthus retroflexus, Digitaria horizontalis, Eleusine indica, Commelina benghalensis e Euphorbia heterophylla. Tolerando a redução da produtividade de até $5 \%$, o PAI foi até 4 DAE; o PTPI, até 32 DAE; e o PCPI com duração de 28 dias, entre 4 e 32 DAE. Quando se admitiu a queda de produtividade equivalente ao desvio-padrão da média do tratamento mantido no limpo, estabeleceu-se o PAI de 1 DAE; PTPI, de 37 DAE; e PCPI durando 36 dias, entre 1 e 37 DAE.
\end{abstract}

Palavras-chave: época de semeadura, espaçamento, Gossypium hirsutum, matocompetição.

\begin{abstract}
Dense sowing of cotton in the "off season" is a strategy adopted by cotton farmers to reduce production costs and increase the profitability of this activity. The objective of this study was to determine the periods of coexistence and weed control in cotton, in seed condensed in the "off season". The experiment was conducted on Farm Pouso Frio in Chapadão do Sul-MS. The cultivar BRS 293 was sown on February $7^{\text {th }}$, 2010, adopting a $0.45 \mathrm{~m}$ spacing between rows at a density of 260,000 seeds ha $\mathrm{h}^{-1}$. The treatments consisted of two groups. In the first one, the crop was maintained in coexistence with weed plants for increasing periods of time after emergence, to determine $P P W C$, whereas in the second group, the cotton remained free from weed competition in the initial periods to determine the TPWC. Analyses wre made of periods of $0,5,10,15,22,29,36$, 43, 50, 57, 64, 71 and 165 days after emergence (DAE) for crop-weed coexistence, or initial weed control. The most important weeds were Bidens pilosa, Amaranthus retroflexus, Digitaria horizontalis, Eleusine indica, Commelina benghalensis and Euphorbia heterophylla. When tolerating reduced productivity of up to 5\%, PPWC lasted up 4 DAE; TPWC, up to 32 DAE and $C P W C$ lasted for 28 days, between 4 and 32 DAE. When considering the reduced productivity equivalent to the standard deviation of the average productivity of the treatment kept in clean, $P P W C$ lasted up to 1 DAE; TPWC, up to 37 DAE, and CPWC lasted for 36 days, between 1 and 37 DAE.
\end{abstract}

Keywords: sowing time, spacing, Gossypium hirsutum, weed competition.

1 Recebido para publicação em 9.12.2013 e aprovado em 2.6.2014.

2 Agro MR Defensivos Agrícolas Ltda, Francisco Alves-PR, Brasil, <michelraimondi@hotmail.com>; ${ }^{3}$ Universidade Estadual de Maringá, Maringá-PR, Brasil; ${ }^{4}$ Terra-Paraná Pesquisa e treinamento Agrícola, Assis Chateaubriand-PR, Brasil.

Planta Daninha, Viçosa-MG, v. 32, n. 3, p. 521-532, 2014 


\section{INTRODUÇÃO}

Preocupados em manter a cotonicultura como uma atividade viável economicamente, os cotonicultores têm buscado estratégias para reduzir os custos de produção e, consequentemente, elevar a rentabilidade final com essa cultura. Uma nova alternativa de manejo adotada foi a semeadura adensada na"safrinha em sucessão à cultura da soja. Uma grande vantagem desse sistema é a redução do ciclo produtivo da cultura, diminuindo assim os custos de produção e elevando a rentabilidade da cultura. O controle precoce do crescimento vegetativo com fitorregulador, a intensa competição entre plantas e a escassez hídrica ao final do ciclo para as semeaduras realizadas na safrinha favorecem potencialmente a precocidade, reduzindo o ciclo da cultura. Com o menor ciclo produtivo do algodoeiro nesse sistema, o período de controle de pragas e doenças é reduzido e, caso a sequência do manejo de pragas e doenças seja mantida, o número de aplicações, consequentemente, deverá ser reduzido. Essa situação, portanto, proporciona menor custo de produção e contribui para maior rentabilidade da atividade.

O cultivo do algodoeiro adensado consiste em utilizar menores espaçamentos entre linhas, se comparado aos tradicionais, que são de 0,76 a 1,00 m. Stephenson et al. (2011) e Reddy et al. (2009) relatam que a denominação de ultra-adensado refere-se à utilização de espaçamentos entre 0,19 e $0,38 \mathrm{~m}$; o adensado, entre 0,39 e 0,76 m; e o espaçamento convencional é aquele adotado a partir de $0,76 \mathrm{~m}$ entre linhas de semeadura. As populações de plantas no cultivo adensado podem variar entre 120 mil e 380 mil plantas ha ${ }^{-1}$, sendo mais comum a utilização de 200 a 250 mil plantas ha ${ }^{-1}$.

As alterações no espaçamento, na densidade de plantas e na época de semeadura induzem uma série de modificações no crescimento e desenvolvimento do algodoeiro e modificam o potencial competitivo das plantas daninhas e da própria cultura, o que pode alterar os períodos de competição (Silva et al., 2006). Entende-se que o espaçamento adensado no algodoeiro resulta em maior capacidade de competição com as plantas daninhas (Molin et al., 2004). Com o aumento da população de plantas, embora a produção de massa seca por planta possa ser reduzida, a cobertura por unidade de área pode ser maior, devido ao maior índice de área foliar. Assim, o fechamento mais rápido da cultura e o maior sombreamento da entrelinha podem proporcionar maior controle cultural das plantas daninhas. Esse fato é explicado por Silva et al. (2006), os quais notaram que com o cultivo adensado passa-se a adotar uma população de plantas bem mais elevada que a semeadura em espaçamentos maiores, o fechamento da área entre as linhas se dá em menor tempo, o índice de área foliar é maior e, consequentemente, maior radiação solar é absorvida e refletida, reduzindo a disponibilidade de radiação na entrelinha da cultura. Ao contrário, teoricamente, a baixa densidade populacional, com arranjos espaciais largos entre as plantas do algodoeiro, resulta em menor poder de competição da cultura e propicia melhores condições de desenvolvimento das plantas daninhas. Segundo Azevêdo et al. (1994), quanto maior o espaçamento entre fileiras, mais amplo foi o PCPI com as plantas daninhas no algodoeiro e, quanto menor o espaçamento, mais curta a duração do PCPI. De acordo com esses autores, na semeadura do algodoeiro em espaçamento de 1,0 m entre linhas o PCPI foi de 30 dias, iniciando-se aos 16 DAE. Com o espaçamento de $0,8 \mathrm{~m}$, iniciou-se aos 18 dias de emergência, com PCPI de 16 dias. Já no espaçamento mais estreito $(0,5 \mathrm{~m})$, o PCPI foi de 12 dias, iniciando-se aos 28 dias após a emergência.

No entanto, com o adensamento das linhas de semeadura e aumento no número de plantas por área, há de se levar em conta o estresse que essas alterações podem causar às plantas cultivadas, em razão da maior competição intraespecífica. Sabe-se ainda que a presença de plantas daninhas mais próximas às linhas de semeadura e da cultura proporciona maior competição. Isso leva à compreensão de que, em espaçamentos adensados, todas as plantas daninhas que compõem a flora infestante estarão competindo diretamente com a cultura, sendo maior a intensidade e o poder de competição devido à proximidade entre ambas. Os efeitos da matocompetição podem ser ainda maiores no início do ciclo do algodoeiro, momento de maior sensibilidade à interferência imposta pelas plantas daninhas, devido ao 
lento crescimento da cultura. Portanto, é possivel que, para a semeadura adensada, realizada na safrinha, a matocompetição se inicie mais precocemente, até mesmo pelo encurtamento do ciclo, se comparada à semeadura realizada no verão e em espaçamentos convencionais. Por outro lado, é provável que o período total em que a cultura necessita ser mantida livre da interferência das plantas daninhas seja menor, quando realizada a semeadura adensada na safrinha, também em função do encurtamento do ciclo produtivo da cultura e do rápido fechamento da entrelinha, ao contrário da semeadura em espaçamento convencional.

Torna-se necessário, portanto, o melhor conhecimento e entendimento dos períodos de competição das plantas daninhas com a cultura, em semeadura adensada. O objetivo deste trabalho foi determinar os períodos de interferência das plantas daninhas no algodoeiro em semeadura adensada na safrinha, nas condições do cerrado brasileiro.

\section{MATERIAL E MÉTODOS}

O trabalho foi desenvolvido durante a safra 2009/2010 na Fazenda Pouso Frio, municipio de Chapadão do Sul-MS, nas coordenadas de latitude de $18^{\circ} 40^{\prime} 48.53^{\prime \prime S}$ e longitude de $52^{\circ} 53^{\prime} 0.67 " \mathrm{O}$, com altitude de $854 \mathrm{~m}$. A semeadura do algodoeiro, cultivar BRS 293, foi feita no dia 07/02/2010, após a colheita da soja, portanto, na safrinha, empregando espaçamento de 0,45 m entre linhas, com densidade de semeadura de 260 mil sementes ha-1, cuja emergência ocorreu no dia 12/02/2010 (70\% das plântulas emergidas em relação à densidade de semeadura).

O solo da área experimental foi classificado como Latossolo Vermelho Distrófico, com textura muito argilosa (Embrapa, 2006). As características químicas e físicas de uma amostra de solo na profundidade de 0-0,2 m foram: $60 \%$ de argila; $29 \%$ de areia; $11 \%$ de silte; $\mathrm{pH}$ em água de 5,$8 ; 4,7 \mathrm{cmol}_{\mathrm{c}} \mathrm{dm}^{-3} \mathrm{de}$ $\mathrm{H}+\mathrm{Al}^{+3} ; 4,6 \mathrm{cmol}_{\mathrm{c}} \mathrm{dm}^{-3}$ de $\mathrm{Ca}^{+2} ; 0,9 \mathrm{cmol}_{\mathrm{c}} \mathrm{dm}^{3}$ de $\mathrm{Mg}^{+2} ; 0,33 \mathrm{cmol}_{\mathrm{c}} \mathrm{dm}^{-3} \mathrm{de} \mathrm{K}^{+} ; 9,85 \mathrm{mg} \mathrm{dm}^{-3}$ de $\mathrm{P}$; e 34,1 $\mathrm{g} \mathrm{dm}^{-3}$ de MO. A precipitação pluvial registrada durante a condução do experimento, assim como a média pluviométrica da região nos últimos dez anos, estão apresentadas na Tabela 1 .

Para o manejo da área antes da semeadura, foram realizadas duas aplicações de herbicidas: a primeira com glyphosate (1.440 g e.a. ha ${ }^{-1}$ ), cinco dias antecedendo a semeadura, e a segunda, um dia antes da semeadura, com paraquat (500 $\left.\mathrm{g} \mathrm{ha}^{-1}\right)$. A adubação na base, por ocasião da semeadura, foi de $150 \mathrm{~kg} \mathrm{ha}^{-1}$ de superfosfato simples (27 kg de $\mathrm{P}_{2} \mathrm{O}_{5}$ ). Duas adubações de cobertura foram realizadas a lanço, com emprego de $80 \mathrm{~kg} \mathrm{ha}^{-1}$ de cloreto de potássio (48 kg de $\mathrm{K}_{2} \mathrm{O}$ ) na primeira aplicação aos 10 DAE e $150 \mathrm{~kg} \mathrm{ha}^{-1}$ de sulfato de amônio (32 kg de $\mathrm{N}$ ) na segunda, aos 25 DAE.

Reguladores de crescimento foram utilizados de acordo com trabalho de Ferrari et al. (2008) e com recomendação agronômica, conforme descrito na Tabela 2. Para maturação uniforme dos frutos, todas as parcelas receberam aplicação de condicionadores de colheita, cujos produtos e doses são descritos na Tabela 2. Todos os demais tratos culturais foram realizados de acordo com o efetuado pelo produtor, igualmente na área comercial por ele conduzida no talhão onde foi feito o experimento, sempre com acompanhamento agronômico.

O experimento foi constituído por dois grupos de tratamentos. No primeiro (G1), destinado à determinação do período anterior à

Tabela 1 - Precipitações pluviais mensais (PM) e acumuladas (PA) registradas durante a condução do trabalho e média dos últimos 10 anos (P10). Chapadão do Sul-MS, 2009/2010

\begin{tabular}{|c|c|c|c|c|c|r|r|r|}
\hline Precipitação & Fev/10 & Mar/10 & Abr/10 & Mai/10 & Jun/10 & Jul/10 & Ago/10 & Set/10 \\
\hline PM & 444 & 150 & 17 & 32 & 0 & 5 & 0 & 0 \\
\hline PA & 444 & 594 & 611 & 643 & 643 & 648 & 648 & 648 \\
\hline P10 & 189 & 233 & 119 & 57 & 16 & 21 & 13 & 47 \\
\hline
\end{tabular}

Fonte: Agência Nacional das Águas e Fazenda Pouso Frio. 
Tabela 2 - Tratamentos e épocas de aplicação dos reguladores de crescimento e condicionador de colheita empregados no algodoeiro. Chapadão do Sul-MS, 2009/2010

\begin{tabular}{|c|c|l|l|c|}
\hline Data & DAE & \multicolumn{1}{|c|}{ Objetivo } & \multicolumn{1}{c|}{ Produto } & $\begin{array}{c}\text { Dose } \\
(\mathrm{L} \mathrm{ha}\end{array}$ \\
\hline $23 / 03 / 10$ & 37 & Regulador de crescimeneto & PIX HC (Cloreto de Mepiquat $\left.-250 \mathrm{~g} \mathrm{~L}^{-1}\right)$ & 0,14 \\
\hline $31 / 03 / 10$ & 47 & Regulador de crescimeneto. & PIX HC (Cloreto de Mepiquat $\left.-250 \mathrm{~g} \mathrm{~L}^{-1}\right)$ & 0,14 \\
\hline $09 / 04 / 10$ & 56 & Regulador de crescimeneto & PIX HC (Cloreto de Mepiquat $\left.-250 \mathrm{~g} \mathrm{~L}^{-1}\right)$ & 0,12 \\
\hline $19 / 04 / 10$ & 66 & Regulador de crescimeneto & PIX HC (Cloreto de Mepiquat $\left.-250 \mathrm{~g} \mathrm{~L}^{-1}\right)$ & 0,10 \\
\hline \multirow{2}{*}{$04 / 07 / 10$} & \multirow{2}{*}{142} & Desfolhante & Dropp Ultra (Diurom+Tidiazurom $\left.-60+120 \mathrm{~g} \mathrm{~L}^{-1}\right)$ & 0,20 \\
\cline { 3 - 6 } & & Maturador & Finish $\left(\right.$ Ciclanilida+Etefom $\left.-60+480 \mathrm{~g} \mathrm{~L}^{-1}\right)$ & 1,70 \\
\hline
\end{tabular}

interferência (PAI), foram avaliados 13 períodos crescentes de convivio da cultura com as plantas daninhas após emergência (DAE): 0,5 , $10,15,22,29,36,43,50,57,64,71$ e 165 dias. Após cada período de convivência, foi realizado o controle (manual) das plantas daninhas até a colheita. No segundo grupo (G2), foram avaliados 13 periodos crescentes de controle das infestantes após emergência: $0,5,10,15,22$, 29, 36, 43, 50, 57, 64, 71 e 165 dias. Após o término de cada período de controle, permitiu-se que as plantas daninhas emergissem livremente, a fim de estimar o período total de prevenção à interferência (PTPI).

O delineamento experimental utilizado foi o de blocos casualizados, com 26 tratamentos e oito repetições. Cada parcela foi constituída de 11 linhas de plantas, com 6 metros de comprimento, com área total de $29,7 \mathrm{~m}^{2}$. A área útil para as avaliações foi de $20,25 \mathrm{~m}^{2}$, composta das linhas centrais, desprezando-se a última linha de cada extremidade lateral, além de 0,5 $\mathrm{m}$ inicial e final de cada parcela.

Ao término de cada período de convivência da cultura com a comunidade infestante (G1) e ao final do ciclo da cultura, para os tratamentos com controle inicial (G2), foi avaliada a ocorrência das plantas daninhas, por meio de quatro áreas amostrais de $0,25 \mathrm{~m}^{2}$, tomadas aleatoriamente na área útil de cada parcela. Para cada espécie de planta daninha, foram determinadas a densidade, massa seca e frequência, a fim de obter o índice de valor de importância (IVI), calculado conforme a fórmula proposta por Mueller-Dombois \& Ellenberg (1974): $I V I=D R+F R+D o R$, em que IVI representa o índice de valor de importância; DR é a densidade relativa de cada espécie (razão entre o número de plantas de uma espécie e o total de plantas amostradas, expressa em porcentagem); FR representa a frequência relativa (frequência com que a espécie ocorreu nas amostragens, expressa em porcentagem); e DoR é a dominância relativa (razão entre a massa seca da espécie e o total de massa seca amostrado, expressa em porcentagem).

A partir desses indices, procedeu-se ao cálculo da importância relativa (IR), utilizando também a fórmula proposta por MuellerDombois \& Ellenberg (1974). A IR é determinada por meio da razão entre o IVI de cada espécie e o somatório dos índices de valor de importância (IVIs) de todas as espécies, expressa em porcentagem (IR = IVI/IVIs).

Aos 100 DAE, para o G1, e somente para este, aferiu-se a transmissividade luminosa no dossel da cultura, que, indiretamente, indica o fechamento desta. Para isso, mediu-se o fluxo luminoso incidente na entrelinha da cultura, com auxílio de um luxímetro, modelo Minipa 1011, em Lux (Lux $=$ lúmen $\left.\mathrm{m}^{-2}\right)$. O equipamento foi disposto ao nivel do solo, precisamente na parte central da entrelinha, em quatro pontos da área útil de cada parcela. Priorizou-se a realização dessa avaliação entre os horários de 12 e 14 horas, nos momentos em que o céu se encontrava sem nuvens.

Ao final do ciclo, imediatamente antes da colheita, foi quantificado o número de plantas de algodão em quatro metros lineares, nas duas linhas centrais de cada parcela. Na mesma ocasião, foi quantificado o número de capulhos por planta, a partir da escolha aleatória de dez plantas, dentro da área útil de cada parcela. 
Quando atingido o ponto de colheita (95\% dos capulhos - 165 DAE), foi realizada a colheita manual dos capulhos nas linhas centrais das parcelas, excluindo uma linha de cada extremidade lateral, além de $0,5 \mathrm{~m}$ da extremidade inicial e final das linhas de cultivo. A massa (g) de algodão em caroço de cada parcela foi extrapolada para arrobas ha ${ }^{-1}$, para análise. A correção da umidade foi realizada pelo método de estufa, e o cálculo da umidade, pela fórmula da umidade em base seca. Os dados de produtividade de algodão em caroço foram utilizados para determinação dos períodos de interferência das plantas daninhas, por meio de análise de regressão. Com base nas equações de regressão ajustadas, foram determinados os periodos de interferência das plantas daninhas para os niveis de tolerância de: a) 5\% na redução da produtividade $=$ admitida a máxima redução na produtividade de algodão em caroço de $5 \%$ em relação ao tratamento mantido livre da interferência das plantas daninhas (Knezevic et al., 2002); e b) desvio-padrão da média $=$ tomou-se como base a redução da produtividade referente ao desvio-padrão da média do tratamento mantido durante todo o ciclo sem a interferência das plantas daninhas.

Os dados foram submetidos aos testes de Levene e Shapiro-Wilk, para avaliar a variância e a normalidade dos erros. Posteriormente, as variáveis analisadas foram submetidas à análise de variância pelo teste $\mathrm{F}(\mathrm{p}<0,05)$ e à análise de regressão dentro de cada grupo. Ou seja, os modelos utilizados em cada subitem foram separadamente discutidos dentro de cada grupo de tratamentos (convivência $=\mathrm{G} 1$; controle $=\mathrm{G} 2$ ).

Os dados de produtividade de algodão em caroço (arrobas ha ${ }^{-1}$ ) referente ao G1 foram ajustados pelo modelo sigmoidal de Boltzmann, $\mathrm{Y}=\mathrm{B}+\{(\mathrm{A}-\mathrm{B}) / 1+\exp [(\mathrm{DAE}-\mathrm{C}) / \mathrm{D}]\}$, em que: $\mathrm{Y}=$ produtividade (arrobas ha $\left.{ }^{-1}\right) ; \mathrm{A}=$ produtividade máxima estimada; $\mathrm{B}=$ produtividade mínima estimada; $\mathrm{DAE}$ = dias após a emergência que a cultura permaneceu em convivência com as plantas daninhas; e C e D = constantes do modelo. Para o G2, a fim de determinar o PTPI, os dados se ajustaram ao modelo sigmoidal, $\mathrm{Y}=\mathrm{A} /\{1+\exp [-(\mathrm{DAE}-\mathrm{B}) / \mathrm{C}]\}$, em que: $\mathrm{Y}=$ produtividade (arrobas ha-1); $\mathrm{A}=$ assintota máxima (arrobas ha $\left.{ }^{-1}\right) ; \mathrm{DAE}=$ dias após a emergência que a cultura permaneceu livre de plantas daninhas; e $\mathrm{B}$ e $\mathrm{C}=$ constantes do modelo.

Os dados obtidos com o luxímetro (transmissividade luminosa) foram ajustados pelo modelo sigmoidal, $\mathrm{Y}=\mathrm{B}+\mathrm{A} /\{1+\mathrm{EXP}[-(\mathrm{DAE}-\mathrm{C}) /$ $\mathrm{D}$ ]), em que: $\mathrm{Y}=$ fluxo luminoso (lúmen $\mathrm{m}^{-2}$ ) incidente nas entrelinhas da cultura; $\mathrm{DAE}=$ dias após a emergência; $\mathrm{B}=$ fluxo luminoso mínimo (lúmen $\mathrm{m}^{-2}$ ); $\mathrm{A}=$ diferença entre $\mathrm{O}$ ponto máximo e o mínimo do fluxo luminoso (lúmen $\mathrm{m}^{-2}$ ); C e D = constantes do modelo.

Os dados originais referentes ao estande final (número de plantas $\mathrm{m}^{-1}$ ) da cultura foram transformados em valores percentuais relativos ao tratamento mantido no limpo. Feito isso, os tratamentos referentes ao $\mathrm{G} 1$ foram ajustados pelo modelo sigmoidal, $\mathrm{Y}=\mathrm{B}+\mathrm{A}$ / $\{1+\mathrm{EXP}[-(\mathrm{DAE}-\mathrm{C}) / \mathrm{D}]\}$, em que: $\mathrm{Y}$ estande final de plantas (\% - relativa ao tratamento mantido no limpo); $\mathrm{DAE}=$ dias após a emergência; $\mathrm{B}=$ estande mínimo (\%); $\mathrm{A}=$ diferença entre $\mathrm{o}$ ponto de máximo e o mínimo do estande final de plantas (\%); e C e D = constantes do modelo. Para os dados obtidos no G2, o modelo utilizado foi o logístico, $\mathrm{Y}=\mathrm{D}+\left(\mathrm{A} / 1+(\mathrm{DAE} / \mathrm{C})^{-\mathrm{B}}\right)$, em que: $\mathrm{Y}=$ estande final de plantas $(\%$ - relativa ao tratamento mantido no limpo); DAE = dias após a emergência; $\mathrm{D}=$ estande mínimo $(\%) ; \mathrm{A}=$ diferença entre o ponto de máximo e o mínimo do estande final de plantas (\%); $\mathrm{C}=$ periodo (DAE) em que ocorre $50 \%$ de resposta do estande (\%); e B = declividade da curva.

Os dados originais referentes ao número de capulhos por plantas foram transformados em valores percentuais relativos ao tratamento mantido no limpo. O G1 ajustou-se ao modelo logístico, $\mathrm{Y}=\mathrm{D}+\left(\mathrm{A} / 1+(\mathrm{DAE} / \mathrm{C})^{-\mathrm{B}}\right)$, sendo: $\mathrm{Y}=$ número $(\%)$ de capulhos por planta; $\mathrm{DAE}=$ dias após a emergência; $\mathrm{D}=$ número $(\%)$ mínimo de capulhos por planta; $\mathrm{A}=$ diferença entre o ponto de máximo e o mínimo do número (\%) de capulhos por planta; $\mathrm{C}=$ período (DAE) em que ocorre $50 \%$ de resposta do número (\%) de capulhos por planta; e B = declividade da curva. Para o segundo grupo de tratamentos (G2), os dados foram ajustados pelo modelo logístico, $\mathrm{Y}=\mathrm{A} /\left[1+(\mathrm{DAE} / \mathrm{C})^{-\mathrm{B}}\right]$, em que: $\mathrm{Y}=$ número $(\%)$ de capulhos por planta; $\mathrm{DAE}=$ dias após a emergência; $\mathrm{A}=$ diferença entre o ponto de máximo e o mínimo do número $(\%)$ de capulhos por planta; $\mathrm{C}=$ período (DAE) 
em que ocorre $50 \%$ de resposta do número de capulhos por planta; e B = declividade da curva.

\section{RESULTADOS E DISCUSSÃO}

A descrição das espécies de plantas daninhas encontradas durante os levantamentos realizados ao longo do ciclo da cultura encontra-se na Tabela 3. Na Figura 1 está demonstrada a densidade total e das principais plantas daninhas do trabalho, referente ao G1. Até 15 DAE houve a maior densidade (386 plantas $\mathrm{m}^{-2}$ ) de plantas daninhas. A partir desse período houve redução na densidade da população infestante, sendo verificada a menor densidade total (99 plantas $\mathrm{m}^{-2}$ ) aos 165 DAE. B. pilosa destacou-se como a espécie de maior densidade, sendo os valores máximos (230 plantas $\mathrm{m}^{-2}$ ) observados aos 5 DAE, com cerca de $61,83 \%$ da densidade total. Esse comportamento decrescente da densidade populacional da comunidade infestante é conhecido e esperado. Nos períodos iniciais ocorre a germinação dos primeiros fluxos de plantas daninhas, muitas vezes beneficiados pela elevada umidade que se encontra no solo na época de semeadura. Após esse período, há redução da densidade das plantas daninhas com o desenvolvimento das próprias infestantes e da cultura, aumentando a competição inter e intraespecífica, em que as plantas mais vigorosas ou que emergiram primeiro sobressaem em relação àquelas menos desenvolvidas ou recém-emergidas, causando a morte destas. Assim, há acúmulo crescente de massa seca por planta e redução da densidade de plantas à medida que o ciclo da cultura avança.

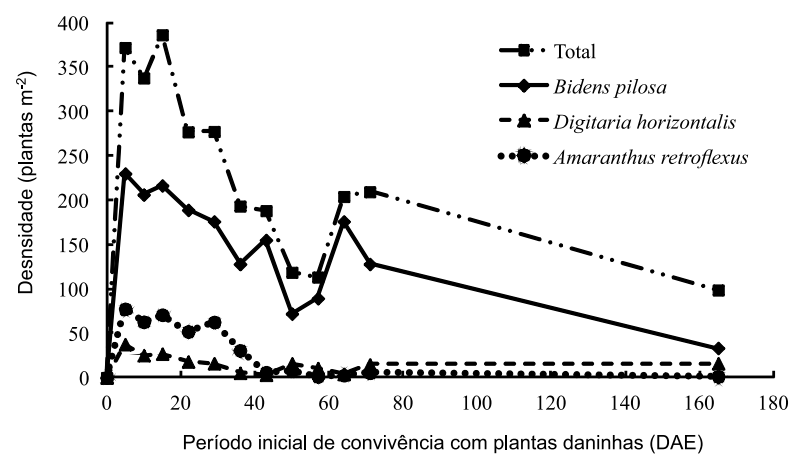

Figura 1 - Densidade total e das principais plantas daninhas presentes no grupo de tratamentos no qual o algodoeiro foi submetido a períodos iniciais de convivência com as plantas daninhas (G1). Chapadão do Sul-MS, 2009/2010.

Tabela 3 - Comunidade infestante encontrada no decorrer do período experimental, com respectivos nomes científicos, nome comum e famílias a que pertencem. Chapadão do Sul-MS, 2009/2010

\begin{tabular}{|c|c|c|}
\hline Espécie & Nome comum & Família \\
\hline \multicolumn{3}{|c|}{ Dicotiledoneae } \\
\hline Bidens pilosa & Picão-preto & \multirow{2}{*}{ Asteraceae } \\
\hline Tridax procumbens & Erva-de-touro & \\
\hline Euphorbia heterophylla & Leiteiro & \multirow{2}{*}{ Euphorbiaceae } \\
\hline Chamaesyce hyrta & Erva-de-santa-luzia & \\
\hline Amaranthus retroflexus & Caruru & \multirow{2}{*}{ Amaranthaceae } \\
\hline Alternanthera tenella & Apaga-fogo & \\
\hline Spermacoce latifolia & Erva-quente & \multirow{2}{*}{ Rubiaceae } \\
\hline Richardia brasiliensis & Poaia-branca & \\
\hline Commelina benghalensis & Trapoeraba & Commelinaceae \\
\hline Portulaca oleracea & Beldroega & Portulacaceae \\
\hline Ipomoea grandifolia & Corda-de-viola & Convolvulaceae \\
\hline Glycine max & Soja & Fabaceae \\
\hline \multicolumn{3}{|c|}{ Monocotiledoneae } \\
\hline Digitaria horizontalis & Capim-colchão & \multirow{3}{*}{ Poaceae } \\
\hline Cenchrus echinatus & Capim-carrapicho & \\
\hline Eleusine indica & Capim pé-de-galinha & \\
\hline
\end{tabular}


Quanto aos tratamentos em que houve períodos iniciais de controle das plantas daninhas (G2), nota-se redução gradativa da densidade total e das principais plantas daninhas quanto maior o período inicial de controle (Figura 2). A maior densidade total (82 plantas $\mathrm{m}^{2}$ ) foi observada aos $22 \mathrm{DAE}$, com maior densidade de $B$. pilosa (44 plantas $\mathrm{m}^{2}$ ) observada nesse período.

A massa seca das plantas daninhas foi crescente até o final do ciclo do algodoeiro para o G1 (Figura 3). O máximo acúmulo de massa seca total (1.294 $\mathrm{g} \mathrm{m}^{2}$ ) foi verificado aos 165 DAE. Esses valores foram beneficiados, principalmente, pelo acúmulo de massa seca de $B$. pilosa, que também registrou acúmulo crescente até os $165 \mathrm{DAE}$, quando promoveu os valores máximos $\left(514 \mathrm{~g} \mathrm{~m}^{-2}\right)$, representando aproximadamente $40 \%$ do acúmulo de massa seca total. Para G2, o maior acúmulo de massa seca se deu no tratamento em que não houve nenhum controle da comunidade infestante (Figura 4). Com o decorrer e aumento dos períodos iniciais com controle das plantas daninhas, registrou-se acúmulo decrescente de massa seca por parte das espécies. Aos $57 \mathrm{DAE}$, as plantas daninhas que emergiram promoveram acúmulo de massa seca referente a $1,88 \%$ da máxima acumulada.

Observando a IR das espécies no G1, a espécie de maior expressão também foi B. pilosa, com os maiores valores de IR $(46,77 \%)$ observados aos 43 DAE (Figura 5). Em seguida, deve ser destacada a espécie A. retroflexus, com maior IR $(19,03 \%)$ aos 29 DAE. C. benghalensis apresentou maiores valores no final do ciclo da cultura, quando promoveu valor de IR de $14,04 \%$ aos 165 DAE. Semelhante ao primeiro grupo de tratamentos, no G2, B. pilosa também foi a principal espécie de planta daninha (Figura 6). A máxima IR desta espécie $(37,45 \%)$ foi observada quando o controle inicial foi realizado até 22 DAE. As gramineas $D$. horizontalis e $E$. indica, além de C. benghalensis, embora com IR inferior ao de B. pilosa, proporcionaram valores sempre acima de $10 \%$ nos períodos avaliados.

B. pilosa é uma espécie de grande ocorrência nas áreas agrícolas do cerrado e seu controle é dificil, tanto na cultura do algodão como em outras, muito em razão da seleção de plantas resistentes aos herbicidas. Quando

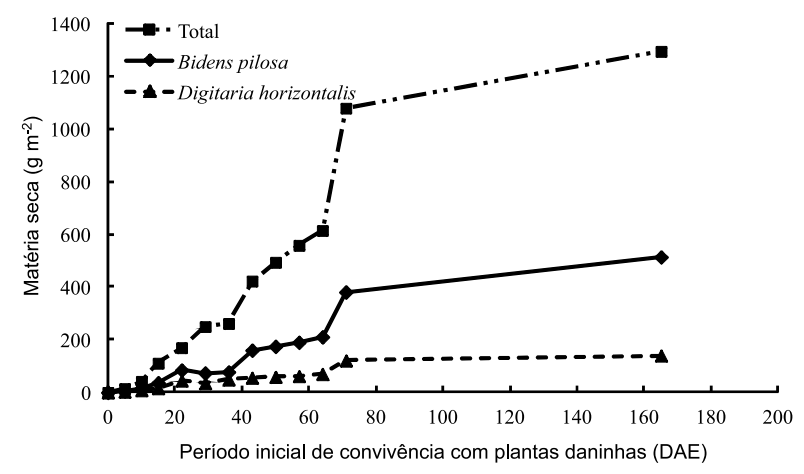

Figura 3 - Massa seca total e das principais plantas daninhas presentes no grupo de tratamentos no qual o algodoeiro foi submetido a períodos iniciais de convivência com as plantas daninhas (G1). Chapadão do Sul-MS, 2009/2010.

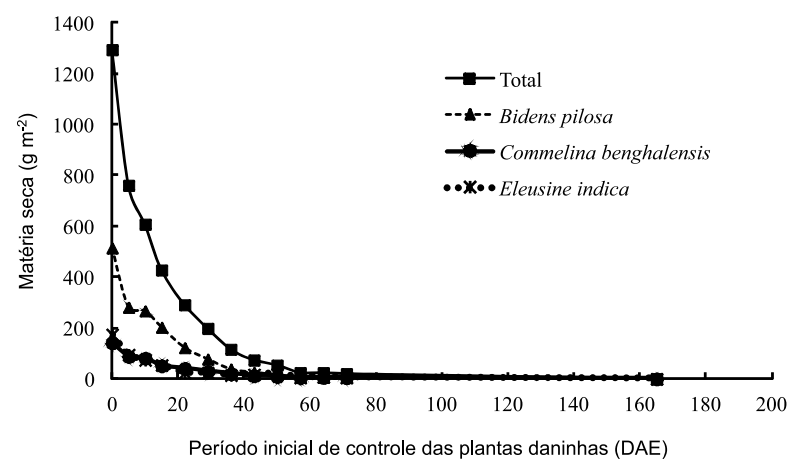

Figura 4 - Massa seca total e das principais plantas daninhas presentes no grupo de tratamentos no qual o algodoeiro foi submetido a períodos iniciais de controle das plantas daninhas (G2). Chapadão do Sul-MS, 2009/2010.

não controladas, ou quando na ocorrência de escapes, sobressaem da cultura e emitem seus capitulos florais, produzindo grande quantidade de sementes viáveis para a germinação nas culturas seguintes. Isso garante que suas populações se mantenham presentes durante os anos agrícolas.

Os dados referentes à avaliação da transmissividade luminosa no dossel da cultura aos 100 DAE estão demonstrados na Figura 7. Observa-se que, pelo ajuste do modelo, as plantas daninhas interferiram negativamente no fechamento da cultura, desde os primeiros dias de convivência. O fluxo luminoso aferido na entrelinha do algodoeiro até os $5 \mathrm{DAE}$ não diferiu daquele do tratamento mantido no limpo, de acordo com o desvio-padrão da média do tratamento mantido no limpo. Após esse 


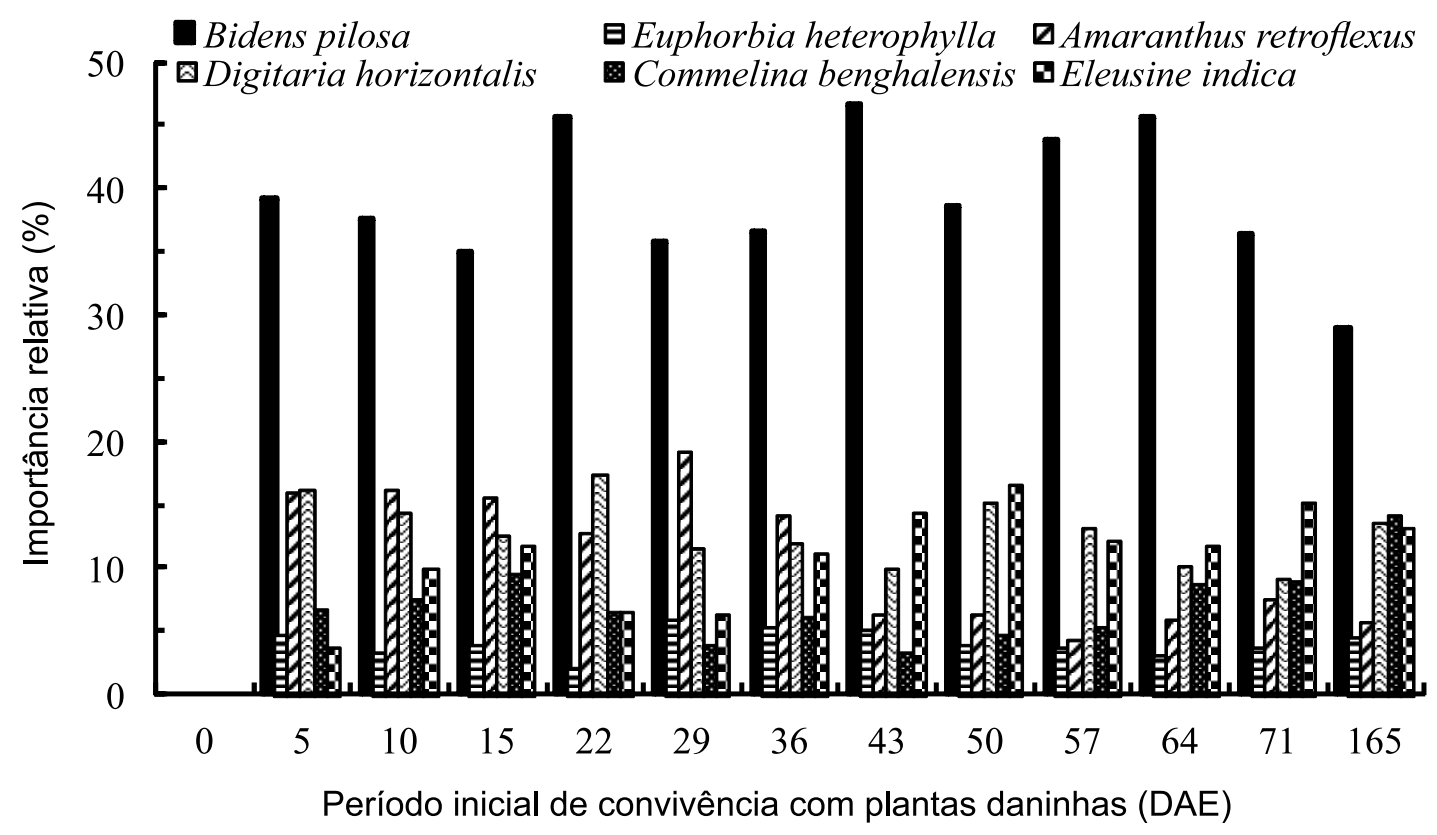

Figura 5 - Importância relativa (IR) das principais espécies de plantas daninhas presentes no grupo de tratamentos no qual o algodoeiro foi submetido a períodos iniciais de convivência com plantas daninhas (G1). Chapadão do Sul-MS, 2009/2010.

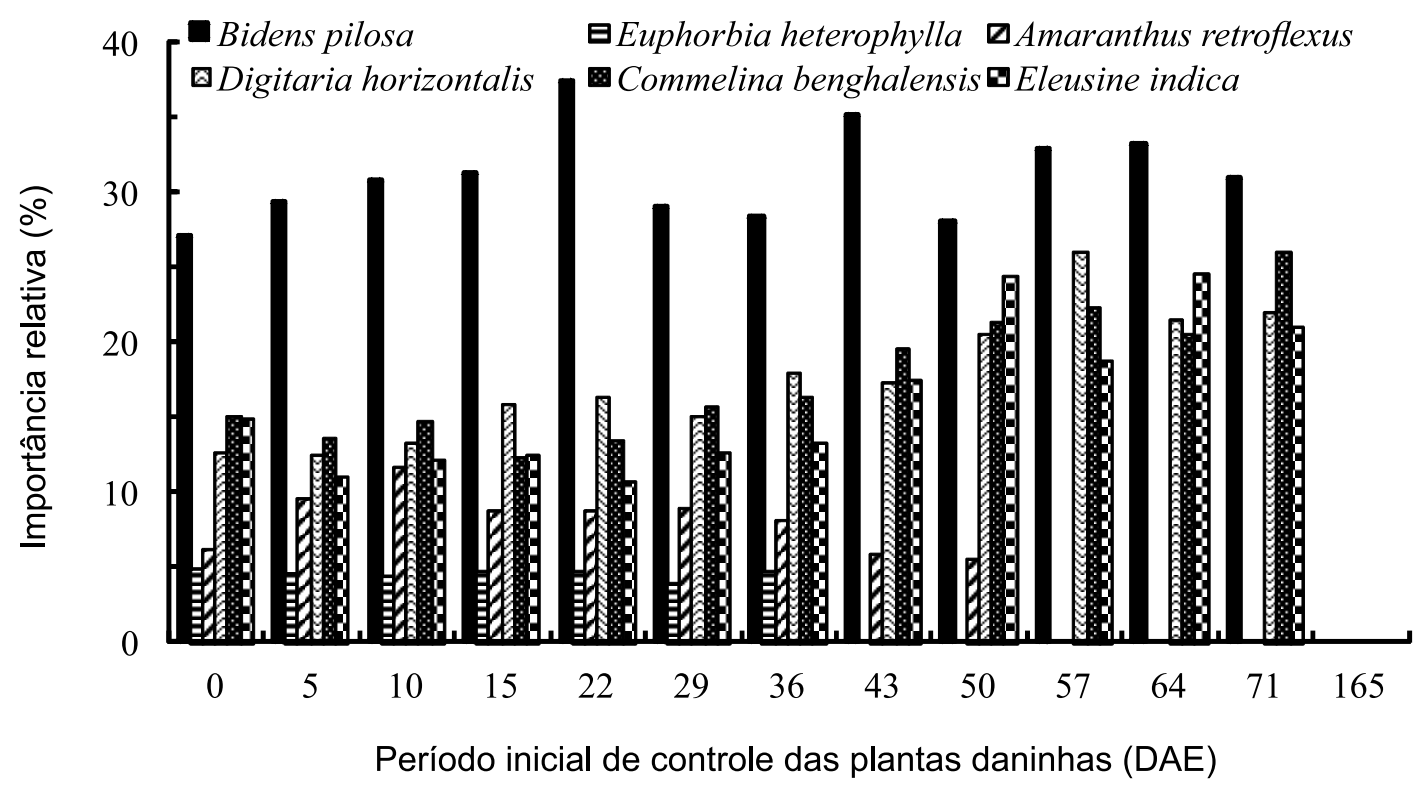

Figura 6 - Importância relativa (IR) das principais espécies de plantas daninhas presentes no grupo de tratamentos no qual o algodoeiro foi submetido a períodos iniciais de controle das plantas daninhas (G2). Chapadão do Sul-MS, 2009/2010.

período, a inclinação da curva demonstra que o algodoeiro passou a ser afetado mais intensamente.

Na Figura 8 estão expostos os dados de estande da cultura, em função dos períodos de convivência ou controle das plantas daninhas. $\mathrm{O}$ estande da cultura sofreu interferência mais intensa a partir de $11 \mathrm{DAE}$, quando em convivência inicial com as plantas daninhas (G1). O convivio entre a cultura e as plantas daninhas durante todo o ciclo promoveu a 


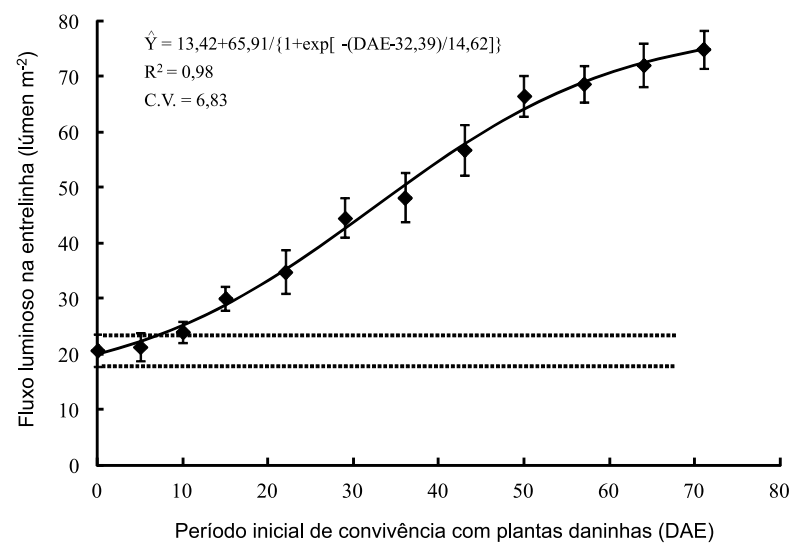

Figura 7 - Fluxo luminoso incidente na entrelinha do algodoeiro (lúmen $\mathrm{m}^{-2}$ ) aos $100 \mathrm{DAE}$ e respectivos desvios-padrão, em função dos períodos de convivência com as plantas daninhas. As linhas pontilhadas indicam o desvio-padrão da média do tratamento mantido no limpo. Chapadão do Sul-MS, 2009/ 2010.

redução de aproximadamente $66 \%$ do estande da cultura. Para o G2, verificou-se que as plantas daninhas ainda promoveram redução no número de plantas quando o controle foi realizado por períodos inferiores a $50 \mathrm{DAE}$ (Figura 8).

A convivência (G1) com as plantas daninhas a partir de $11 \mathrm{DAE}$ interferiu negativamente no número médio de capulhos por planta (Figura 9). Por outro lado, é indispensável que o controle das plantas daninhas seja realizado até aproximadamente $67 \mathrm{DAE}$ (grupo 2), pois, quando a cultura foi mantida livre da presença de plantas daninhas por períodos inferiores a este, o número de capulhos ainda foi influenciado pela competição das plantas daninhas. Como neste sistema o número de maçãs por planta é limitado, geralmente se deseja obter entre 3 e 5 de maçãs por planta, a redução precoce no número dessas estruturas, em detrimento da competição exercida pelas plantas daninhas, pode resultar em danos irreversiveis e impactos severos à produtividade do algodoeiro.

Segundo Rajcan et al. (2004) e Vidal et al. (2008), em busca de maior competitividade perante as plantas daninhas, a cultura promove alterações fisiológicas, principalmente em relação ao balanço de fotoassimilados, destinando maior quantidade destes ao desenvolvimento vegetativo. Com isso, devido à forte relação fonte-dreno nessa cultura, o desenvolvimento de raízes, por exemplo, é muito prejudicado, o que certamente influenciará a absorção de nutrientes, acarretando prejuízos futuros à cultura.

Na Figura 10 estão inseridas as equações para os dados de produtividade referentes aos modelos ajustados, tanto para o grupo de tratamentos que foram submetidos a periodos iniciais de convivência (PAI) como para o

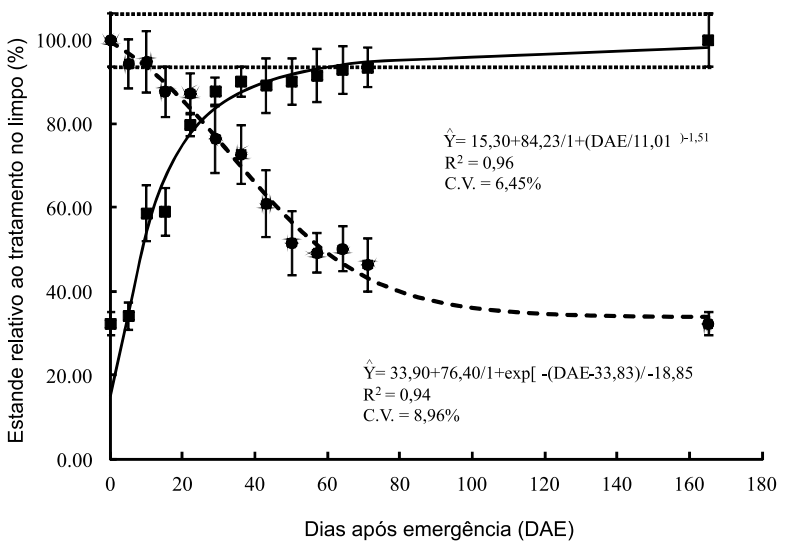

Figura 8 - Estande final de plantas relativo ao tratamento mantido no limpo em função dos períodos iniciais de convivência (•) e de controle (ם) das plantas daninhas e respectivos desvios-padrão. As linhas pontilhadas indicam o desviopadrão da média do tratamento mantido no limpo. Chapadão do Sul-MS, 2009/2010.

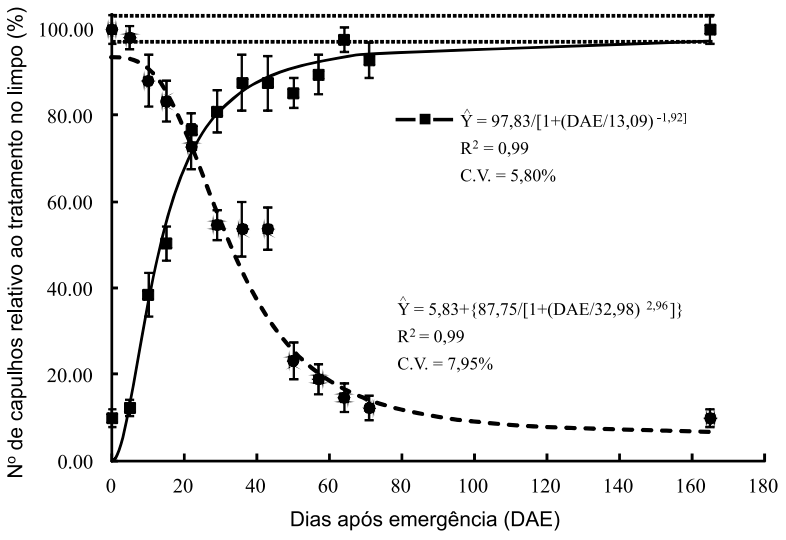

Figura 9 - Número médio de capulhos por planta relativo ao tratamento mantido no limpo em função dos períodos iniciais de convivência $(\bullet)$ e de controle $(\boldsymbol{\square})$ das plantas daninhas e respectivos desvios-padrão. As linhas pontilhadas indicam o desvio-padrão da média do tratamento mantido no limpo. Chapadão do Sul-MS, 2009/2010. 


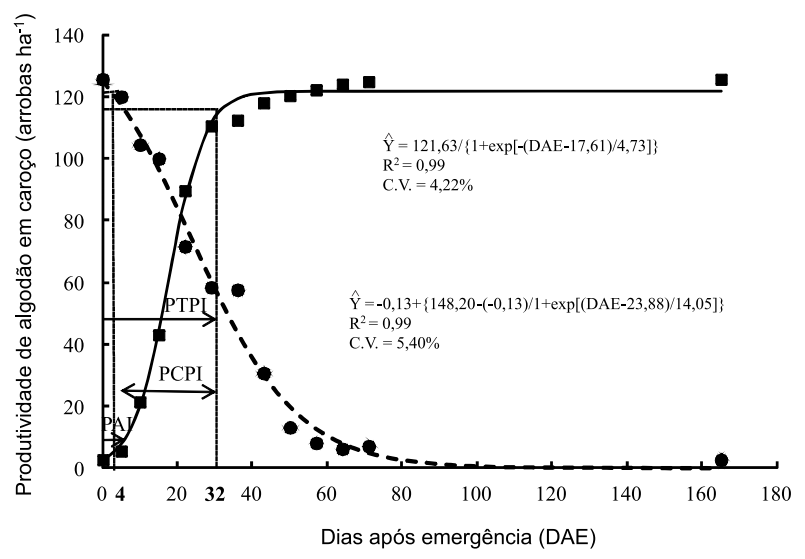

Figura 10 - Produtividade de algodão em caroço, período anterior à interferência (PAI), período total de prevenção da interferência (PTPI) e período crítico de prevenção da interferência (PCPI), em função dos períodos crescentes de convivência $(\bullet)$ e de controle $(\boldsymbol{\square})$ das plantas daninhas, considerando-se a perda de produtividade de $5 \%$. Chapadão do Sul-MS, 2009/2010.

segundo grupo de tratamento, no qual foram mantidos por períodos iniciais de controle das plantas daninhas (PTPI). Nos tratamentos com convivência inicial entre as plantas daninhas e a cultura (G1), considerando perda de $5 \%$ na produtividade em relação ao tratamento mantido ausente de competição, verificou-se que a convivência com as plantas daninhas começou a afetar a cultura (PAI) já aos quatro dias após a sua emergência. Nessa data, a cultura encontrava-se ainda em fase de emergência, porém, mesmo nesta fase precoce de desenvolvimento da cultura, já foi estabelecido um processo de interferência das plantas daninhas.

Uma vez que os principais efeitos de interferência, nesse caso, estão associados à competição por recursos do meio, é improvável que limitações por água e nutrientes possam ser significativas num estádio tão precoce de desenvolvimento. Lembrando que foi realizada adubação no sulco no momento da semeadura e que precipitações ocorreram antes e imediatamente depois da semeadura, esses danos podem estar relacionados a outros fatores, provavelmente pela competição de luz. Vidal et al. (2008) afirmam que a competição por luz no início do ciclo do algodoeiro é mais prejudicial do que a competição por água e nutrientes, levando a acreditar que, para o presente trabalho, esta seja a provável causa da expressiva redução inicial da produtividade. Segundo Ballaré \& Casal (2000), em uma cultura onde há plantas daninhas, estas podem alterar, além da quantidade, a qualidade da luz incidente no solo e, assim, afetar o desenvolvimento da cultura. A variação na qualidade da luz é percebida por pigmentos como o fitocromo, criptocromo e fitotropina (Lamego et al., 2005; Vidal et al., 2008). A relação da radiação vermelho extremo/vermelho, percebida pelos pigmentos, tem papel importante na indução de muitas alterações morfológicas na arquitetura das plantas, como crescimento do caule, dominância apical e ramificação (Ballaré \& Casal, 2000; Liu et al., 2009; Green-Tracewicz et al., 2011). A detecção de elevada quantidade de radiação vermelho extremo, que geralmente ocorre na presença de plantas daninhas, faz com que as plantas aloquem maior disponibilidade de recursos para o crescimento da parte aérea e menor quantidade para o seu sistema radical e, nesse sentido, pode comprometer posteriormente a disputa por recursos do solo (Rajcan \& Swanton, 2001; Rajcan et al., 2004).

Ao ocorrer o encurtamento no ciclo produtivo da cultura, como verificado neste trabalho, principalmente pela época tardia de semeadura do algodoeiro e restrição hídrica ao final do ciclo, é justificável que também haja redução nos períodos de competição, tanto em relação ao PAI como para os demais períodos. No mais, para Silva \& Nepomuceno (1991), em trabalho com girassol, a utilização de diferentes densidades de plantas ocasiona competições intraespecíficas de intensidades variáveis. A maior população de plantas empregada na semeadura realizada na safrinha pode contribuir para elevada competição dentro da própria cultura, ou pelo menos causar uma condição de estresse nas plantas cultivadas, que as tornem ainda mais suscetiveis à matocompetição, principalmente no início do ciclo.

No G2, estabeleceu-se o PTPI até 32 DAE; assim, o PCPI teve duração de 28 dias, entre 4 e 32 DAE (Figura 10). Além da própria redução no ciclo produtivo do algodoeiro, pode-se atribuir esse menor PTPI ao rápido fechamento da cultura, quando realizada a semeadura em espaçamentos mais estreitos. Essa condição 
propicia maior controle cultural das plantas daninhas, pois o sombreamento da entrelinha impede o estabelecimento das novas populações de plantas daninhas. Silva et al. (2006) notaram que, como o sistema adensado de plantio do algodoeiro passa a adotar população de plantas bem mais elevada que a semeadura em espaçamentos maiores, o fechamento da entrelinha se dá em menor tempo, pois o índice de área foliar é maior e, consequentemente, maior radiação solar é absorvida e refletida, reduzindo a disponibilidade de radiação na entrelinha da cultura. Esse raciocínio está em concordância com Azevêdo et al. (1994), os quais verificaram que a redução no espaçamento contribui para a redução do PCPI, sendo de 30 dias no espaçamento de $1,00 \mathrm{~m}$, 16 dias no espaçamento de $0,80 \mathrm{~m}$ e 12 dias no espaçamento de $0,50 \mathrm{~m}$ entre as fileiras. Rogers et al. (1976) estudaram a influência de espaçamento entre fileiras sobre plantas daninhas, observando que, quando elas eram mais fechadas $(0,53 \mathrm{~m})$, o rendimento máximo foi obtido quando a cultura permaneceu no limpo durante as seis primeiras semanas. Com fileiras mais espaçadas $(1,06 \mathrm{~m})$, o periodo necessário para um rendimento máximo foi de 10 a 14 semanas sem competição.

Se adotado como nível de tolerância o desvio-padrão da média relativo à produtividade do tratamento mantido no limpo, que foi de 1,94 arroba ha $^{-1}$, a produtividade do algodoeiro foi afetada negativamente quando a cultura conviveu com as plantas daninhas por mais de um dia após sua emergência (PAI). Esse resultado demonstra que semeaduras realizadas na safrinha, em sistema adensado, não toleram a convivência com as plantas daninhas sem que ocorram danos à produtividade. No G2, conclui-se que o controle das plantas daninhas se faz necessário (PTPI) por períodos superiores a 37 DAE, para que não haja danos maiores à produtividade do que os normalmente toleráveis. O período em que necessariamente é imprescindivel o controle das plantas daninhas (PCPI) foi de 36 DAE: entre 1 e 37 DAE.

Foi constatada alta correlação negativa da massa seca das plantas daninhas com a produtividade, o estande, o número de capulhos e a transmissividade luminosa no dossel da cultura (Tabela 4) para o G1 e G2, sendo as maiores correlações observadas no G2. De forma semelhante, a densidade de plantas daninhas apresentou correlações negativas com as variáveis do G2. Esse fato indica que, quanto maior o acúmulo de massa seca e maior a reinfestação das plantas daninhas, após o período de controle inicial, menores foram a produtividade, o estande, o número de capulhos e a transmissividade luminosa no dossel da cultura. No entanto, a correlação de massa seca com as variáveis do G2 foi maior que a verificada para densidade de plantas, indicando que a segunda é menos determinante que a primeira para determinação dos períodos de convivência das plantas daninhas nessa cultura. Ainda, a densidade de plantas daninhas resultou em correlação não significativa com as variáveis analisadas no G1. Esses resultados se devem à elevada densidade de plantas daninhas nos primeiros períodos de competição e à gradativa redução desta ao longo do ciclo do algodoeiro, concomitantemente com a perda de produtividade da cultura pelo aumento dos períodos de convivência.

Conclui-se que no sistema de semeadura adensada do algodoeiro na safrinha não há tolerância de convivência entre a cultura e as plantas daninhas, uma vez que a produtividade é afetada significativamente nos primeiros dias após a emergência da cultura.

Tabela 4 - Correlação linear de Pearson entre massa seca (MS) e densidade de plantas (DP) com a produtividade, estande, número de capulhos e transmissividade luminosa (TL)

\begin{tabular}{|c|c|c|c|c|c|c|c|}
\hline & \multicolumn{2}{|c|}{ Produtividade } & \multicolumn{2}{c|}{ Estande } & \multicolumn{2}{c|}{ № de capulhos $^{\mathrm{TL}^{\underline{1} /}}$} \\
\cline { 2 - 8 } & Grupo 1 & Grupo 2 & Grupo 1 & Grupo 2 & Grupo 1 & Grupo 2 & Grupo 1 \\
\hline MS & $-0,8453^{*}$ & $-0,9325^{*}$ & $-0,9106^{*}$ & $-0,9513^{*}$ & $-0,8819^{*}$ & $-0,9534^{*}$ & $0,9220^{*}$ \\
\hline DP & $0,4118^{\text {ns }}$ & $-0,7487^{*}$ & $0,4473^{\text {ns }}$ & $-0,7418^{*}$ & $0,4236^{\text {ns }}$ & $-0,7362^{*}$ & $-0,3789^{\text {ns }}$ \\
\hline
\end{tabular}

${ }_{1}^{1}$ Avaliado somente nos tratamentos do grupo 1 ; * significativo a $5 \%$ pela análise de correlação linear de Pearson; ${ }^{\text {ns }}$ não significativo a $5 \%$ pela análise de correlação linear de Pearson. 
Admitindo perda máxima de $5 \%$ da produtividade, determinaram-se os períodos de $4 \mathrm{e}$ 32 para o PAI e o PTPI, respectivamente, com duração do PCPI de 28 dias: entre 4 e 32 DAE. Aceitando a redução da produtividade relativa ao desvio-padrão do tratamento mantido no limpo, estabeleceram-se os períodos de $1 \mathrm{e}$ 37 DAE para o PAI e o PTPI, respectivamente, e o PCPI com duração de 36 dias, entre 1 e 37 DAE. Por ser um cálculo estatístico e fácil de ser estimado nos trabalhos científicos, o desvio-padrão da média do tratamento mantido no limpo é o mais indicado como nível de tolerância para determinar os períodos de controle e convivência das plantas daninhas no algodoeiro. Bidens pilosa foi a planta daninha de maior importância; a informação referente à massa seca das plantas daninhas foi mais importante do que a densidade das plantas daninhas, pois foi a característica que mais se correlacionou com a produtividade do algodoeiro, podendo ser um indicativo importante dos períodos de convivência e controle das plantas daninhas.

\section{LITERATURA CITADA}

AZEVÊDO, D. M. P. et. al. Período crítico de competição entre as plantas daninhas e o algodoeiro anual irrigado. Pesq. Agropec. Bras., v. 29, n. 9, p. 1417-1425, 1994.

BALLARÉ, C. L.; CASAL, J. J. Light signals perceived by crop and weed plants. Field Crops Res., v. 67, n. 2, p. 149-160, 2000.

\section{EMPRESA BRASILEIRA DE PESQUISA}

AGROPECUÁRIA - EMBRAPA. Centro Nacional de Pesquisa de Solos. Sistema brasileiro de classificação de solos. 2.ed. Rio de Janeiro: 2006. 306 p.

FERRARI, S. et al. Desenvolvimento e produtividade do algodoeiro em função de espaçamentos e aplicação de regulador de crescimento. Acta Sci. Agron., v. 30, n. 3, p. 365-371, 2008.

GREEN-TRACEWICZ, E. et. al. Shade avoidance in soybean reduces branching and increases plant-to-plant variability in biomass and yield per plant. Weed Sci., v. 59, n. 1, p. 43-49, 2011.

KNEZEVIC, S. Z. et. al. Critical period for weed control: the concept and data analysis. Weed Sci., v. 50, n. 6, p. 773-786, 2002.

Planta Daninha, Viçosa-MG, v. 32, n. 3, p. 521-532, 2014
LAMEGO, F. P. et. al. Tolerância à interferência de plantas competidoras e habilidade de supressão por cultivares de soja - I. Resposta de variáveis de crescimento. Planta Daninha, v. 23, n. 3, p. 405-414, 2005.

LIU, J. G. et al. The importance of light quality in crop-weed competition. Weed Res., v. 49, n. 2, p. 217-224, 2009.

MOLIN, W. T. et al. Prickly sida (Sida spinosa L.) and spurge (Euphorbia hyssopifolia L.) response to wide row and ultra narrow row cotton (Gossypium hirsutum L.) management systems. Weed Biol. Manag., v. 4, n. 4, p. 222-229, 2004.

MUELLER-DOMBOIS, P.; ELLENBERG, H. Aims and methods of vegetation ecology. New York: John Willey \& Sons, 1974. 547 p.

RAJCAN, I.; SWANTON, C. L. Understanding maize-weed competition: resource competition, light quality and the whole plant. Field Crops Res., v. 71, n. 2, p. 139-150, 2001.

RAJCAN, I. et. al. Red-far-red ratio of reflected light: a hypothesis of why early-season weed control is important in corn. Weed Sci., v. 52, n. 5, p. 774-778, 2004.

REDDY, K. N. et al. Narrow-row cotton production under irrigation and non-irrigated environment: plant population and lint yield. J. Cotton Sci., v. 13, n. 1, p. 48-55, 2009.

ROGERS, N. K. et. al. Influence of row spacing on weed competition with cotton. Weed Sci., v. 24, n. 2, p. 410-413, 1976.

SILVA, P. R. F.; NEPOMUCENO, A. L. Efeito de arranjo de plantas no rendimento de grãos, componentes do rendimento, teor de óleo e no controle de plantas daninhas em girassol. Pesq. Agropec. Bras., v. 26, n. 9, p. 1503-1508, 1991.

SILVA, A. V. et. al. Crescimento e desenvolvimento do algodoeiro em diferentes configurações de semeadura. Bragantia, v. 65, n. 3, p. 407-411, 2006.

STEPHENSON, D. O. et al. Effect of twin-row planting pattern and plant density on cotton growth, yield, and fiber quality. J. Cotton Sci., v. 15, n. 3, p. 243-250, 2011.

VIDAL, R. A. et. al. Initialism: a new term to describe the first mechanism of negative interaction between weeds and crops. J. Plant. Dis. Protec., v. 21, n. 1, p. 95-98. 2008. 